\title{
Mathematical Integral
}

National Cancer Institute

\section{Source}

National Cancer Institute. Mathematical Integral. NCI Thesaurus. Code C94928.

A summation of many products, each being a successive value of a dependent variable y multiplied by a small increment delta $\mathrm{x}$ in the value of its independent variable. 